Tersedia online di: http://ejournal-balitbang.kkp.go.id/index.php/jkpi
e-mail:jkpi.puslitbangkan@ gmail.com
JURNAL KEBIJAKANPERIKANANINDONESIA
Volume 10 Nomor 1 Mei 2018
p-ISSN: 1979-6366
e-ISSN: 2502-6550
Nomor Akreditasi Kementerian RISTEKDIKTI: 21/E/KPT/2018

\title{
KONTRIBUSI RANTAI NILAI TERHADAP PENINGKATAN DAYA SAING PERIKANAN TUNA DI KABUPATEN CILACAP DAN SEKITARNYA
}

\section{CONTRIBUTION OF VALUE CHAIN TOWARD ENHANCEMENT COMPETITIVENESS OF TUNA FISHERY INDUSTRIES IN CILACAP AND SURROUND}

\author{
Bambang Nariyono*1, Arief Daryanto1, M. Firdaus ${ }^{2}$ dan Setijadi Johar ${ }^{1}$ \\ 'Program Studi Manajemen dan Bisnis Sekolah Pascasarjana IPB, Jl. Raya Padjadjaran Kampus Gunung Gede, Bogor \\ Jawa Barat, Indonesia \\ ${ }^{2}$ Fakultas Ekonomi dan Manajemen Institut Pertanian Bogor, JI. Lingkar Akademik Kampus IPB Dramaga Bogor, Jawa \\ Barat, Indonesia \\ Teregistrasi I tanggal: 07 Desember 2017; Diterima setelah perbaikan tanggal: 06 Maret 2018; \\ Disetujui terbit tanggal: 07 Maret 2018
}

\begin{abstract}
ABSTRAK
Indonesia dalam industri tuna sangat diperhitungkan karena posisinya sebagai pemasok lebih dari $15 \%$ produksi tuna dunia, tetapi di sisi lain daya saing industri perikanan tuna masih rendah. Tujuan dari penelitian ini adalah menganalisis kontribusi rantai nilai perikanan tuna terhadap daya saing industri perikanan tuna di Kabupaten Cilacap. Penelitian dilaksanakan pada bulan April sampai dengan September 2017. Hasil analisis Second Order Structural Equation Modeling didapatkan bahwa rantai nilai berpengaruh terhadap daya saing industri tuna dengan loading factor 0.540 dan nilai $p$ yang signifikan. Pengujian terhadap model secara simultan terbukti bahwa model telah fit dengan telah dipenuhinya semua ukuran fitting model yang diindikasikan dengan nilai Chi-Square kecil yaitu 301.252, $\mathrm{RMSEA}=0.072, \mathrm{GFI}=0.907, \mathrm{CFI}=0.923$, dan CMIN/ $\mathrm{DF}=1.814$. Temuan penelitian ini membuktikan bahwa rantai nilai mempunyai pengaruh yang signifikan terhadap daya saing industri tuna. Dengan demikian strategi yang tepat untuk memperkuat daya saing industri tuna dapat dilakukan dengan cara meningkatkan rantai nilai perikanan tuna terutama dari aspek operasional, outbond logistic, dan services.
\end{abstract}

Kata Kunci: Industri tuna; Rantai nilai; Structural Equation Modeling (SEM)

\begin{abstract}
Indonesia is the world's largest have a significant role in the world's tuna produser with contributing more than 5 percent to the world's tuna market the industry. However, competitiveness of tuna fishery industry is still low. The aim of this research is to analyze the contribution of value chain of tuna fishery to the competitiveness of tuna fishery industry in Cilacap. The study was conducted from April to September 2017. The results of analysis using using second order Structural Equation Modeling method (SEM) analysis found that the value chain influenced the competitiveness of tuna industry with loading factor of 0.540 and significant $p$ value. Tests on the model simultant proved that the model requirement fittings of the model. It gives indication with variables value, such as: net Value of Chi-square is low with value 301.252 ; (low) to increase 0.072 for Root Mean Square Error of Approximation (RMSEA); 0.907 for Goodness Fit Index (GFI); 0.907 for (CFI); and 1.814 for minimum discrepancy (CMIN/DF). The results suggested that value chain has a significant impact toward competitiveness of tuna fishery industries. The best strategies to increase competitiveness of tuna fishery industries is increasing a value chain of of tuna fishery industries, Mainly from operational aspect, outbond logistic and services.
\end{abstract}

Keywords: Tuna Fishery Industries; Value Chain; Structural Equation Modeling (SEM) 


\section{PENDAHULUAN}

Indonesia sebagai salah satu negara yang mempunyai stok ikan tuna tebesar, seharusnya dapat mengusai pasar secara global. Dalam bisnis ikan tuna, Indonesia sangat diperhitungkan karena berhasil memasok lebih dari 15\% produksi tuna dunia yang sebesar 6,8 juta metrik ton (FAO, 2014; Lailossa, 2015). Rata-rata produksi tuna Indonesia mencapai lebih dari 1,1 juta ton/tahun. Indonesia saat ini menduduki peringkat ke lima di dunia setelah Thailand, China, Spanyol dan Equador dengan nilai ekspor lebih kurang sebesar US\$765 juta (Galland, G et al., 2016).

Salah satu pelabuhan ikan samudra yang ada di Indonesia berada di Kabupaten Cilacap. Posisi geografis yang langsung menghadap Samudera Hindia menjadikan Cilacap merupakan wilayah perairan laut di Indonesia yang sangat strategis (Suhana, 2015; PPS Cilacap, 2016; DKP Jateng, 2016). Akan tetapi daya saing ekspor ikan tuna dari Kabupaten Cilacap sangat rendah. Hingga tahun 2014, untuk $1 \mathrm{~kg}$ ikan tuna Cilacap hanya dihargai rata-rata $\$ 4,72$ per $\mathrm{kg}$ atau sekitar Rp.61.000 dengan kurs Rp.13.000/ US $\$$. Padahal untuk tahun yang sama harga ekspor dunia ikan tuna bisa mencapai $\$ 7$ hingga $\$ 9$ per $\mathrm{kg}$ atau sekitar Rp.91.000 sd Rp.117.000.

Dengan mengacu kepada latar belakang dan perumusan masalah, maka tujuan penelitian ini adalah untuk menganalisis pengaruh rantai nilai terhadap peningkatan daya saing ikan tuna di Kabupaten Cilacap dan menetapkan strategi yang efektif untuk meningkatkan daya saing industri perikanan tuna.

\section{BAHASAN \\ PERIKANAN TUNA DI CILACAP}

Pelabuhan Perikanan Samudra (PPS) Cilacap merupakan satu diantara beberapa pelabuhan perikanan samudra yang penting di Indonesia. Pada saat ini, PPS Bitung masih merupakan pelabuhan pendaratan ikan terbesar di Indonesia, diikuti PPS Nizam Jakarta, dan PPS Cilacap. Dari segi komoditas yang dihasilkan, tuna menduduki komoditas nomor dua setelah udang dalam nilai ekspor hasil perikanan. Dari 9 jenis tuna dan like tuna, produksi tuna Indonesia di ketiga pelabuhan samudra tersebut didominasi oleh skipjack tuna yang mencapai sekitar $46 \%$, sedang untuk yellofin tuna (YFT) mencapai sekitar $23 \%$, dan bigeye tuna (BET) sekitar $23 \%$ selebihnya tuna jenis lain.

Rata-rata ekspor ikan tuna Kabupaten Cilacap bisa mencapai 3.178,94 ton per tahun sepanjang periode 2010 - 2014, dengan jumlah terbanyak ikan tuna kaleng sekitar $2.365,37$ ton per tahun $(74,41 \%)$, kemudian tuna segar sebesar 624,82 ton per tahun $(19,66 \%)$, dan tuna pouch sebanyak 188,75 ton per tahun (5,94\%). Data dari Badan Pusat Statistik tahun 2017, secara umum nilai eksport tuna dari kabupaten Cilacap mengalami peningkatan yang cukup signifikan, dari Rp. 36.800.469.389 pada tahun 2014 menjadi Rp. 88.851.542.371 pada tahun 2016. Akan tetapi jika dicermati terdapat penurunan yang drastic pada komoditi jenis BLT, dari 34.543 pada tahun 2014 menjadi 2.023 pada tahun 2016 (Tabel 1).

Pemerintah telah melakukan upaya untuk peningkatan produksi perikanan tangkap melalui program yang dinamakan dengan istilah 'Minapolitan'. Program tersebut diatur dalam Peraturan Menteri Kelautan dan Perikanan No.12/MEN/2010 tentang Minapolitan. Minapolitan adalah suatu konsepsi pembangunan ekonomi bidang kelautan dan perikanan yang berbasis kawasan berdasarkan prinsip-prinsip terintegrasi, efisiensi, berkualitas, dan percepatan dimana PPS Cilacap merupakan 1 dari 9 PPS yang akan dijadikan program minapolitan. Konsep minapolitan, menuntut peningkatan suberdaya manusia dan sumberdaya alam serta pemutakhiran teknologi yang ditunjang oleh system koordinasi antar lembaga untuk dapat menghasilkan daya saing yang tinggi. 
Tabel 1. Produksi dan nilai produksi tuna pada Pelabuhan Perikanan Samudra Cilacap 2014-2016

Tabel 1. Value and Production of tuna in Cilacap Ocean fishing port 2014-2016

\begin{tabular}{|c|c|c|c|c|c|c|}
\hline \multirow{3}{*}{ jenis ikan } & \multicolumn{6}{|c|}{ tahun } \\
\hline & \multicolumn{2}{|c|}{2014} & \multicolumn{2}{|c|}{2015} & \multicolumn{2}{|c|}{2016} \\
\hline & volume & nilai & volume & nilai & volume & nilai \\
\hline BLT & 34,543 & $503,250,000$ & 78,215 & $1,110,025,788$ & 2,023 & $21,580,000$ \\
\hline FRI & - & - & 4,235 & $63,150,000$ & 876 & $8,760,000$ \\
\hline KAW & 200 & $2,600,000$ & 16 & 240,000 & 254 & $7,620,000$ \\
\hline SKJ & 664,183 & $10,202,927,363$ & $1,887,001$ & $30,148,396,000$ & 457,222 & $6,358,772,149$ \\
\hline ALB & 77,405 & $1,939,768,000$ & 268,565 & $6,712,685,000$ & 781,533 & $19,395,521,000$ \\
\hline YFT & 131,737 & $4,511,847,335$ & 300,806 & $8,375,747,131$ & 635,955 & $19,683,008,130$ \\
\hline SBT & 88 & $3,520,000$ & 735 & $29,400,000$ & 6,449 & $257,960,000$ \\
\hline BET & 553,270 & $19,636,556,690$ & 903,779 & $30,713,400,552$ & $1,360,376$ & $43,118,321,092$ \\
\hline \multirow[t]{2}{*}{ LOT } & - & - & - & - & - & - \\
\hline & $1,461,426$ & $36,800,469,389$ & $3,443,352$ & $77,153,044,470$ & $3,244,688$ & $88,851,542,371$ \\
\hline
\end{tabular}

Sumber: Statistik Perikanan BPS 2017

RANTAI NILAI, DAYA SAING DAN KERANGKA PENELITIAN

Konsep rantai nilai sebenarnya sudah diperkenalkan sejak lama. Namun baru populer setelah dikenalkan konsep klaster modern yang kenalkan oleh Porter, (1990). Konsep rantai nilai dan klaster merupakan konsep untuk meningkatkan daya saing melalui konsentrasi geografis berbagai perusahaan dan institusi yang saling berhubungan pada sektor tertentu (Porter, 2004) dengan tujuan umum memeriksa semua aktivitas perusahaan manufaktur dan melihat hubungan aktivitas (Acharyulu et al., 2015). Klaster mendorong industri untuk bersaing satu sama lain. Nilai penggunaan gabungan sama dengan jumlah nilai yang dirasakan dari berbagai hasil aktivitas bisnis dan total biaya yang dikeluarkan (Ebders et al., 2000).

Teori model rantai nilai terdiri dari lima aktivitas utama dan empat aktivitas pendukung (Kumar et al., 2013). Teori rantai nilai Porter dapat digunakan untuk mengidentifikasi pembentukan klaster dalam pengembangan industri perikanan terutama industri tuna, aktivitas primer sebagai variabel laten dibentuk oleh indikator-indikator dari inbound logistics, operations, outbound logistic, marketing and sales dan service (Porter, 1985).

Porter mempromosikan rantai nilai (value chain) dalam klaster industri sebagai faktor utama yang membentuk daya saing. Kontribusi Porter adalah menjelaskan hubungan antara firm-industry-country. Lebih jauh, Porter menegaskan bahwa kata kunci dalam pengembangan klaster adalah daya saing. Daya saing sangat bergantung pada produktivitas (Kim, 1985; Ondrej \& Jiri, 2012), sementara produktivitas terletak pada kemampuan industri dalam menciptakan produk dan/atau jasa (Felipe, 1997; Porter, 1998; O'Mahony \& Vecchi, 2002). Porter juga mengemukakan bahwa model penciptaan daya saing yang self-reinforcing sebagai poin utama dari Diamond Porter Model (Porter, 1990; Pavlina, 2015) (Gambar 1).

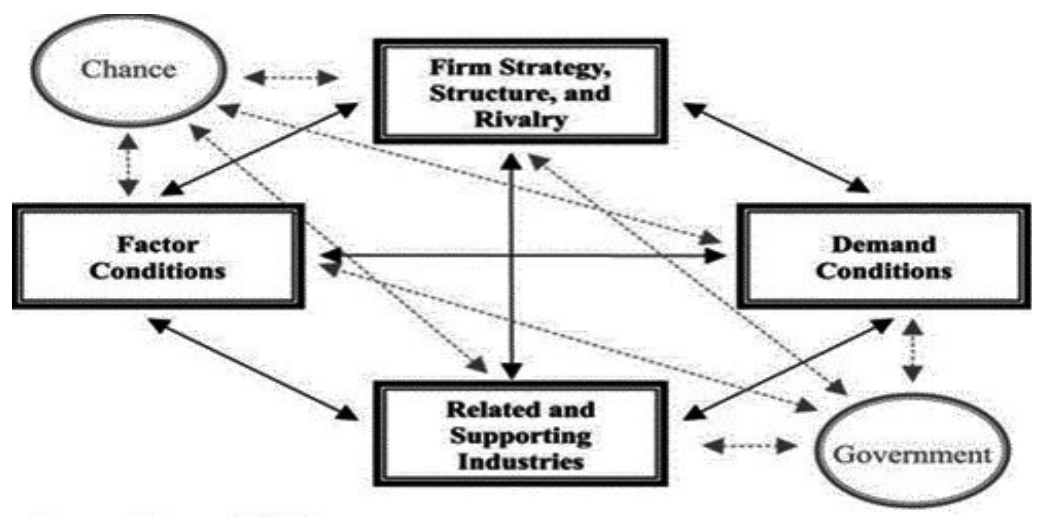

Source: Porter (1990)

Gambar 1. Model diamond porter.

Figure 1. Diamond porter model. 
Penelitian ini difokuskan di Kabupaten Cilacap, dan wilayah lain yang berkaitan dengan industri Tuna, untuk responden pedagang besar dan eksportir Tuna di laksanakan di Jakarta. Unit analisis adalah stakeholder industri perikanan tuna di Kabupaten Cilacap yakni: nelayan ikan tuna, perusahaan perikanan, industri berbasis ikan tuna, pedagang besar, eksportir, TPI, PPS Cilacap, pengusaha pabrik es, perbankan, dan sebagainya yang terintegrasi semuanya dalam rantai nilai industri ikan tuna. Pengumpulan data dilakukan dengan menggunakan kuesioner. Suatu kuesioner dikatakan tepat, cermat dan valid jika pertanyaan pada kuesioner tersebut mampu mengungkapkan apa yang akan diukur. Hasil validasi disajikan pada Tabel 2.

Tabel 2. Hasil validasi dengan bivariate correlation untuk tiap variabel

Table 2. Validation results with bivariate correlation for each variable

\begin{tabular}{llllllr}
\hline \multicolumn{1}{c}{ Variable } & & \multicolumn{5}{c}{ Nilai korelasi terhadap indikatornya } \\
\hline AURN & Pearson Correlation & $.836^{* *}$ & $.671^{* *}$ & $.855^{* *}$ & $.836^{* *}$ & $.819^{* *}$ \\
APRN & Pearson Correlation & $.876^{* *}$ & $.680^{* *}$ & $.874^{* *}$ & $.908^{* *}$ & 1 \\
KFIT & Pearson Correlation & $.713^{* *}$ & $.771^{* *}$ & $.903^{* *}$ & $.890^{* *}$ & 1 \\
KPIT & Pearson Correlation & $.825^{* *}$ & $.862^{* *}$ & $.806^{* *}$ & 1 & \\
FSSP & Pearson Correlation & $.807^{* *}$ & $.927^{* *}$ & $.897^{* *}$ & $.919^{* *}$ & 1 \\
FTIM & Pearson Correlation & $.761^{* *}$ & $.877^{* *}$ & $.889^{* *}$ & 1 & \\
DPIT & Pearson Correlation & $.866^{* *}$ & $.962^{* *}$ & $.863^{* *}$ & $.913^{* *}$ & 1 \\
KBIT & Pearson Correlation & $.832^{* *}$ & $.950^{* *}$ & $.870^{* *}$ & $.884^{* *}$ & 1 \\
\hline
\end{tabular}

Dari Tabel 2 tersebut, terlihat nilai bivariate correlation dari semua variabel yang digunakan sigifikan pada $\alpha=0.05$ (2-tailed), maupun pada $\alpha$ $=0.01$ (1-tailed). Sehingga dapat disimpulkan bahwa semua indikator yang digunakan untuk mengukur variabel adalah valid.

Dalam penelitian ini teknik pengambilan sampel wilayah dilakukan dengan teknik purposive sampling. Purposive sampling dilakukan mengingat tidak semua pelaku usaha yang terkait dengan perikanan tuna memahami permasalahan tuna sehingga perlu dilakukan pemilihan responden yang sesuai. Teknik pengambilan sampel untuk pelaku usaha yang digunakan dalam penelitian ini adalah teknik sampel klaster (Cluster Sampling). Selain itu metode cluster digunakan untuk menjamin tiap kelompok usaha (cluster) dapat terwakili. Untuk unit usaha terdapat 20 unit usaha yang menjadi unit analisis dalam penelitian ini yang respondennya terdiri dari pengurus dan karyawan di unit usaha tersebut.

Teknik pengolahan dan analisis data dalam penelitian ini terdiri dari teknik analisis deskriptif dan inferensial. Analisis data deskriptif dimaksudkan untuk memperoleh gambaran awal dari obyek penelitian dan karakteristik penyebaran skor untuk setiap konstruk yang diteliti. Sedangkan untuk analisis inferensial dimaksudkan untuk menguji hipotesis penelitian menggunakan pemodelan Second-Order SEM (Structural Equation Modeling).

Metode SEM digunakan untuk menganalisa, mensimulasikan relasi ketergantungan antara struktural model dan hubungan antara indikator dan pengukuran model (Crisci, 2012). SEM digambarkan sebagai kombinasi antara CFA (Confirmatory Factor Analysis) dan regresi berganda (Ullman, 2001). Sedangkan CFA digunakan untuk mengukur dan menganalisis faktor-faktor yang menentukan kinerja rantai nilai dan daya saing industri tuna (Maat et al., 2015; Safiih \& Azreen, 2016). CFA dipilih untuk memperbaiki dan memvalidasi skala pengukuran (AlHawari et al., 2005). CFA melibatkan spesifikasi dari satu atau lebih model dari struktur faktor dimana masing-masing model mengusulkan seperangkat variabel laten (Doll et al., 1995; Dimitrov, 2006).

\section{MODEL KONSEPTUAL}

Model konseptual analisis rantai nilai dan klaster dalam rangka peningkatan daya saing industri tuna dapat ditunjukkan oleh Gambar 2. 


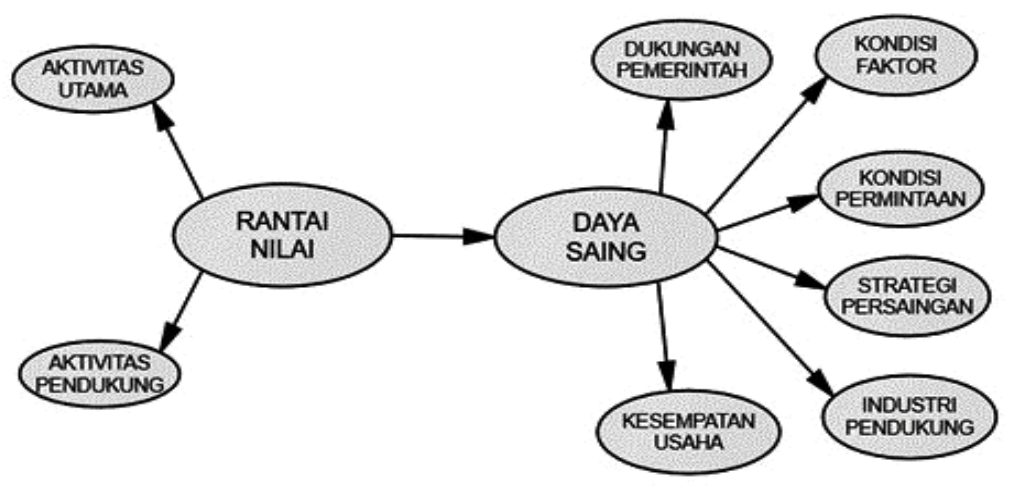

Gambar 2. Model konseptual penelitian.

Figure 2. Conceptual model of research.

Didasarkan pada model konseptual yang telah dibangun pada gambar, maka pengujian hipotesis pada penelitian ini dapat dirumuskan sebagai berikut:

$\mathrm{H}_{0}=$ tidak terdapat pengaruh yang signifikan antara rantai nilai terhadap daya saing industri tuna

$\mathrm{H}_{1}=$ Terdapat pengaruh yang signifikan antara rantai nilai terhadap daya saing industri tuna

Penarikan kesimpulan dilakukan dengan cara menganalisa nilai loding factor yang terkait. Selain dari loading factor, ada indikator lain yang harus digunakan untuk menguji signifikansi dari model penelitian secara struktural (SEM) yaitu menggunakan nilai indeks GFI, AGFI, RMSEA, TLI, CFI, dan $p$ value.

\section{Validitas dan Reliabilitas Model}

Uji validitas dilakukan menggunakan Confirmatory Factor Analysis (CFA). Sedangkan untuk uji relabilitas konstruk dilakukan dengan cara menghitung nilai Cunstruct Reliability yang dilakukan terhadap setiap konstruk yang digunakan untuk membangun model penelitian tersebut.

\section{Variabel Laten Sistem Rantai Nilai (RNIT)}

Uji validitas konstruk sistem rantai nilai industri tuna (RNIT) menggunakan Confirmatory Factor Analysis (CFA) menghasilkan output pada Gambar 3 , yang menggambarkan model CFA second order. Yang dimaksud dengan CFA second order adalah suatu kontruk diukur oleh konstruk lain, dalam hal ini konstruk rantai nilai diukur menggunakan 2 konstruk lain yaitu kontruk aktivitas utama rantai nilai (AURN) dan konstruk aktivitas pendukung rantai nilai (APRN).

Ringkasan fitting model hasil uji Confirmatory Factor Analysis terhadap konstruk RNIT disajikan pada Tabel 3, dimana model belum fit yang diindikasikan dengan hanya ada satu indikator yang memenuhi ukuran fitting model. Artinya model belum bisa menggambarkan perilaku dari sistem rantai nilai atau belum valid.

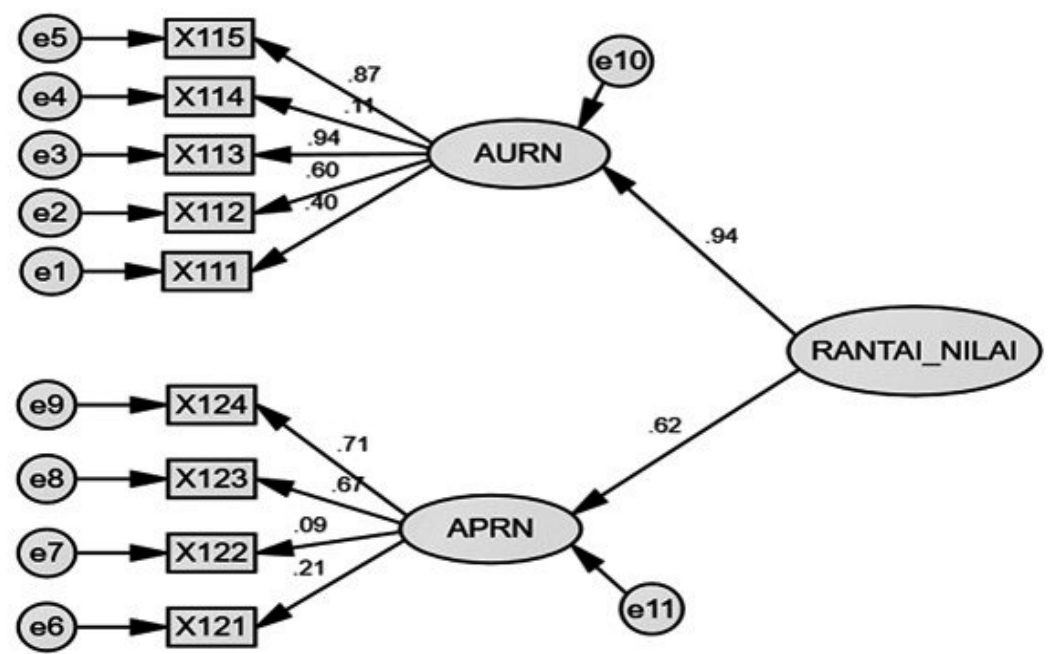

Gambar 3. Hasil running pada AMOS 23 variabel laten rantai nilai (RNIT).

Figure 3. Results running on AMOS 23 latent value chain variables (RNIT). 
Tabel 3. Tabel kebaikan model variabel Sistem rantai nilai (RNIT)

Table 3. Table of goodness of the variable model the value chain system (RNIT)

\begin{tabular}{lccc}
\hline \multicolumn{1}{c}{$\begin{array}{c}\text { Ukuran } \\
\text { Goodness } \text { Of } \text { Fit }\end{array}$} & Standar Kebaikan & Hasil Perhitungan & Kesimpulan \\
\hline CHI-SQUARE & kecil & 121.132 & Tidak fit \\
RMSEA & $\leq 0.080$ & 0.117 & Tidak fit \\
GFI & $\geq 0.900$ & 0.901 & Fit \\
CFI & $\geq 0.900$ & 0.847 & Tidak fit \\
CMIN/DF & $\leq 2.000$ & 3.530 & Tidak fit \\
\hline
\end{tabular}

Langkah pertama untuk membuat model fit adalah dengan memeriksa nilai loading factor dari indikator. Pada output Amos 23 terlihat bahwa indikatorindikator X111, X114, X121 dan X122 mempunyai nilai loading factor sangat kecil yaitu $0.39,0.11,0.21$ dan 0.09. Perbaikan model dilakukan dengan mengeluarkan keempat indikator yang mempunyai loading factor kecil tersebut. Hasil uji model setelah dilakukan revisi ditunjukkan oleh Gambar 4.

Hasil uji model RNIT setelah perbaikan disajikan pada Tabel 4, dimana model telah memenuhi semua ukuran fitting modelyang dipersyaratkan, yang berarti model telah valid.

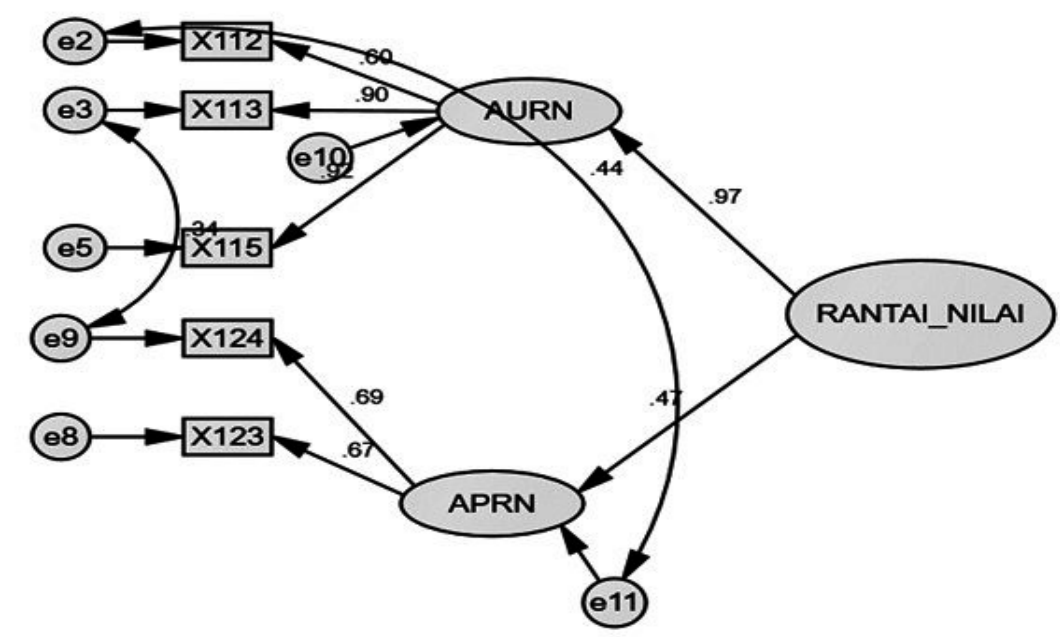

Gambar 4. Hasil running pada AMOS 23 variabel laten RNIT setelah perbaikan.

Figure 4. Results running on AMOS 23 latent variables RNIT after improvement.

Tabel 4. Nilai kebaikan model Sistem Rantai Nilai (RNIT) setelah perbaikan

Table 4. The value of the Value Chain System model (RNIT) after improvement

\begin{tabular}{lccc}
\hline \multicolumn{1}{c}{$\begin{array}{c}\text { Ukuran } \\
\text { Goodness } \text { Of Fit }\end{array}$} & Standar Kebaikan & Hasil Perhitungan & Kesimpulan \\
\hline CHI-SQUARE & kecil & 5.742 & Fit \\
RMSEA & $\leq 0.080$ & 0.075 & Fit \\
GFI & $\geq 0.900$ & 0.954 & Fit \\
CFI & $\geq 0.900$ & 0.971 & Fit \\
CMIN/DF & $\leq 2.000$ & 1.843 & Fit \\
\hline
\end{tabular}

Langkah selanjutnya adalah penghitungan nilai reliabilitas menggunakan Construc realiability. Perhitungan nilai reliability menggunakan data loading factor yang dihitung berdasarkan pada Tabel 5 . Tabel
5 adalah merupakan hasil output dari pengolahan data konstruk RNIT menggunakan metode CFA yang menunjukkan nilai loading factor konstruk dan indikator yang membentuk model RNIT valid. 
Tabel 5. Hubungan variabel Sistem Rantai Nilai (RNIT) terhadap indikatornya

Table 5. Relation of Value Chain System variable (RNIT) to the indicator

\begin{tabular}{|c|c|c|c|c|c|}
\hline & Estimate & $\begin{array}{l}\text { Loading } \\
\text { Factor }\end{array}$ & S.E. & C.R. & $\mathbf{P}$ \\
\hline AURN & 4.035 & 0.970 & 0.428 & 9.428 & $\star \star \star \star *$ \\
\hline APRN & 0.616 & 0.467 & 0.112 & 5.522 & $* * *$ \\
\hline X112 & 1.000 & 0.595 & & & \\
\hline X113 & 1.534 & 0.897 & 0.152 & 10.108 & $* * *$ \\
\hline X115 & 1.435 & 0.921 & 0.141 & 10.211 & $* * *$ \\
\hline $\mathrm{X} 123$ & 3.955 & 0.653 & 0.461 & 8.572 & $* * *$ \\
\hline $\mathrm{X} 124$ & 5.349 & 0.681 & 0.620 & 8.634 & $* * *$ \\
\hline
\end{tabular}

Contruct Reliability $=\frac{\left(\sum \text { standardiz e loading }\right)^{2}}{\left(\sum \text { standardiz e loading }\right)^{2}+\sum \varepsilon j}$

Contruct Reliability $=\frac{(5.184)^{2}}{(5.184)^{2}+2.943}=0.901$
Dari Tabel 4 terlihat bahwa variable RNIT setelah dilakukan perbaikan telah valid. Dengan cara yang sama, dapat dihitung nilai reliabilitas dan validitas konstruk daya saing. Hasilnya dapat ditunjukkan pada Gambar 5 dan Tabel 5.

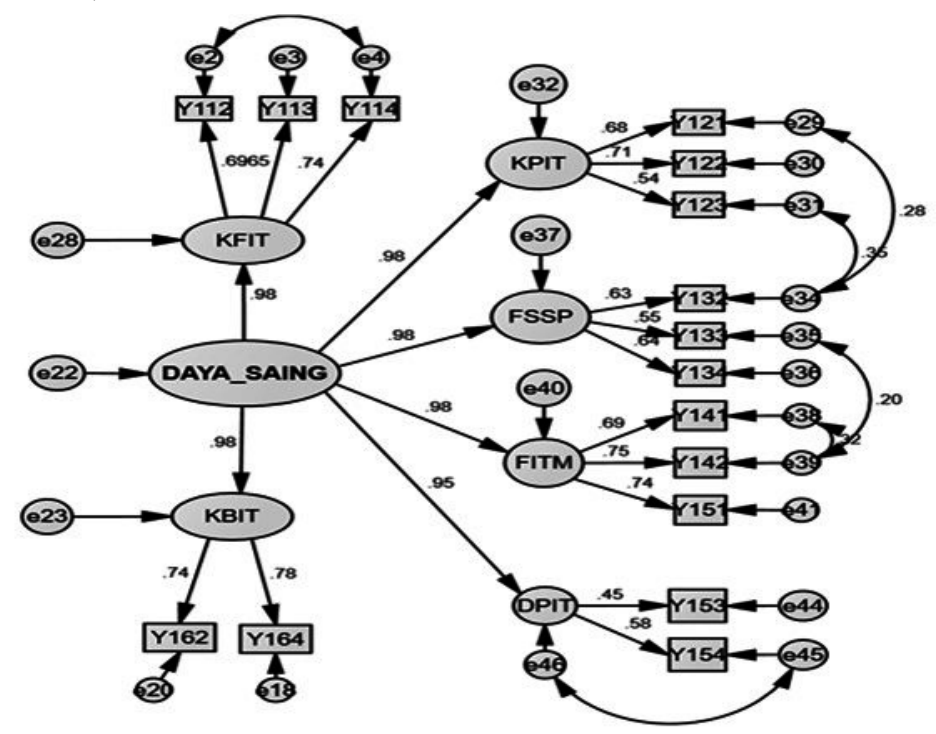

Gambar 5. Model akhir konstruk konstruk daya saing.

Figure 5. The final model of competitiveness constructs.

Hasil perhitungan validitas dan reliabilitas dari Tabel 6 sebagai berikut: konstruk rantai nilai dan daya saing disajikan pada

Tabel 6. Ringkasan validitas dan reliabilitas model

Table 6. Summary of model validity and reliability

\begin{tabular}{rrrcrl}
\hline KONSTRUK & UKURAN & NILAI & KESIMPULAN & $\begin{array}{c}\text { CUNSTRUCT } \\
\text { RELIABILITY }\end{array}$ & KESIMPULAN \\
\hline \multirow{2}{*}{ RANTAI NILAI } & RMSEA $=$ & 0.075 & & & \\
& GFI $=$ & 0.954 & & & \\
CFI $=$ & 0.971 & & & \\
& CMIN/DF $=$ & 1.843 & VALID & 0.901 & RELIABEL \\
\hline \multirow{2}{*}{ DAYA SAING } & RMSEA $=$ & 0.073 & & & \\
& GFI $=$ & 0.911 & & & \\
& CFI $=$ & 0.945 & VALID & 0.976 & RELIABEL \\
\hline
\end{tabular}




\section{Evaluasi Kesesuaian terhadap Model Lengkap dan Reliabilitas Model.}

Model konseptual yang diusulkan dalam penelitian ini kemudian diterjemahkan kedalam model SEM menjadi model pertama atau model awal dalam penelitian ini disajikan pada Gambar 6 .

Selanjutnya dilakukan pengujian dengan menggunakan data penelitian. Hasil dari output running model penelitian menggunakan Amos 23 ditunjukkan pada Tabel 7.
Dari Table 7 tersebut, terlihat bahwa semua ukuran fitting model tidak dapat dipenuhi. Oleh karena itu dilakukan perbaikan terhadap model penelitian. Langkah pertama dari perbaikan model adalah dengan meneliti apakah ada indikator penelitian yang tidak signifikan, yang diindikasikan oleh nilai $p$ value yang lebih besar dari nila á yang digunakan dalam pemodelan. Jika ada indikator yang mempunyai $p$ value yang tidak signifikan, maka indikator tersebut harus dikeluarkan dari model penelitian, karena indikator tersebut bukan pengukur konstruk yang valid. Hasil perbaikan model disajikan pada Gambar 7.

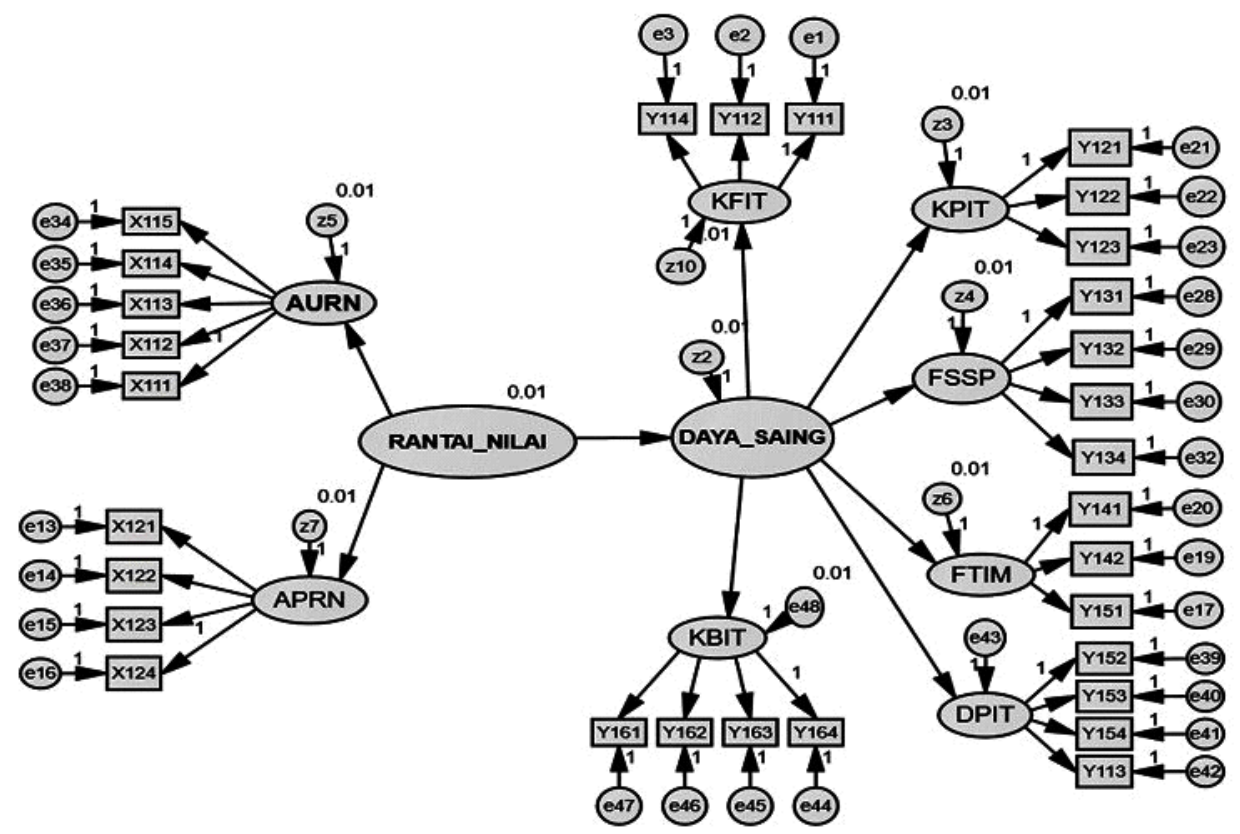

Gambar 6. Model penelitian lengkap.

Figure 6. Complete research model.

Tabel 7. Nilai kebaikan model second order Structural Equation Model(SEM)

Table 7. Goodness value of second order Structural Equation Model (SEM)

\begin{tabular}{lccc}
\hline \multicolumn{1}{c}{$\begin{array}{c}\text { Ukuran } \\
\text { Goodness } \text { Of Fit }\end{array}$} & Standar Kebaikan & Hasil Perhitungan & Kesimpulan \\
\hline CHI-SQUARE & kecil & 736.241 & Tidak fit \\
RMSEA & $\leq 0.080$ & 0.125 & Tidak fit \\
GFI & $\geq 0.900$ & 0.736 & Tidak fit \\
CFI & $\geq 0.900$ & 0.747 & Tidak fit \\
CMIN/DF & $\leq 2.000$ & 3.298 & Tidak fit \\
\hline
\end{tabular}


Tabel 9. Hasil perhitungan model lengkap Table 9. Completed model calculation results

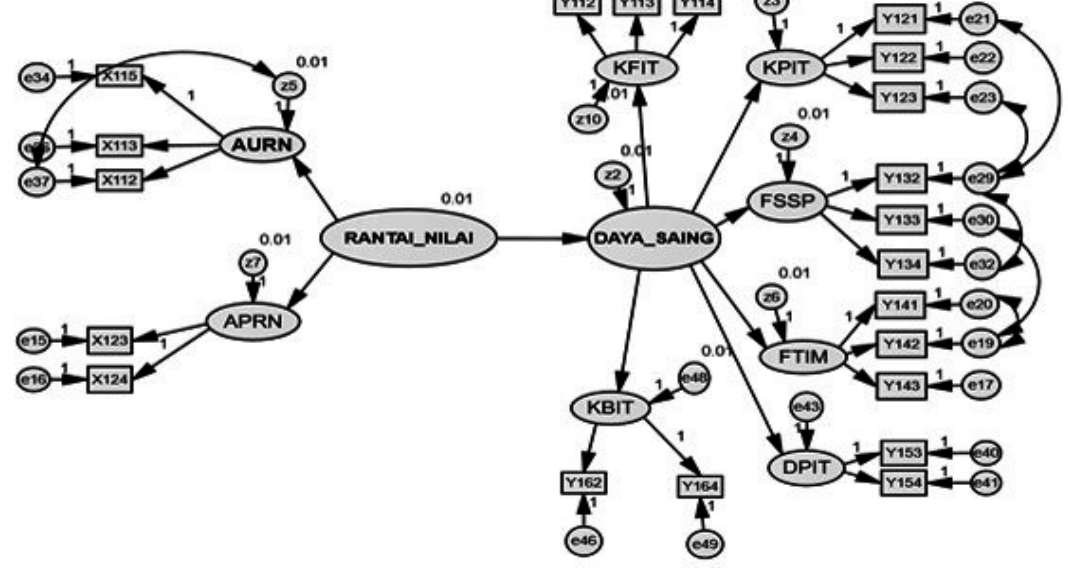

Gambar 7. Output path diagram model penelitian.

Figure 7. Output path diagram of the research model.

Dari hasil perhitungan dengan AMOS 23.0 model dirangkum dalam Tabel 8: pada Gambar 7, tampak ukuran Goodness of Fit

Tabel 8. Nilai kebaikan model second order Structural Equation Model(SEM)

Table 8. Goodness value of second order Structural Equation Model (SEM)

\begin{tabular}{lccc}
\hline \multicolumn{1}{c}{ Ukuran } & Standar Kebaikan & Hasil Perhitungan & Kesimpulan \\
\hline CHI-SQUARE & kecil & 301.252 & Fit \\
RMSEA & $\leq 0.080$ & 0.072 & Fit \\
GFI & $\geq 0.900$ & 0.903 & Fit \\
CFI & $\geq 0.900$ & 0.923 & Fit \\
CMIN/DF & $\leq 2.000$ & 1.814 & Fit \\
\hline
\end{tabular}

Berdasarkan lima ukuran kebaikan model yang disajikan pada Tabel 8, tampak bahwa secara keseluruhan model sudah fit. Dengan demikian model dapat digunakan untuk analisis pengaruh sistem rantai nilai dan produktivitas perikanan tuna terhadap daya saing industri perikanan tuna di Kabupaten Cilacap. Makna dari hasil penelitian ini adalah bahwa model yang telah disusun secara keseluruhan adalah sudah

Tabel 9. Hasil perhitungan model lengkap Table 9. Completed model calculation results baik yang ditandai dengan dipenuhinya semua ukuran fitting model.

Selanjutnya, dilakukan pengujian secara terpisah maupun secara serentak. Pengujian secara terpisah dimaksudkan untuk mengetahui apakah variabelvariabel laten yang digunakan untuk membangun model tersebut. Berikut data hasil perhitungan dengan AMOS 23.0 disajikan pada Tabel 9.

\begin{tabular}{lllcrcr}
\hline \multicolumn{1}{c}{ VAR ENDOGEN } & & VAR EXOGEN & LOADING FACTOR & S.E. & C.R. & P \\
\hline DAYA_SAING & $<---$ & RANTAI_NILAI & 0.54 & 0.066 & 9.676 & $* * *$ \\
KPIT & $<---$ & DAYA_SAING & 0.978 & 0.328 & 11.965 & $* * *$ \\
FSSP & $<---$ & DAYA_SAING & 0.974 & 0.352 & 10.327 & $* * *$ \\
KFIT & $<---$ & DAYA_SAING & 0.98 & 0.315 & 13.303 & $* * *$ \\
FTIM & $<---$ & DAYA_SAING & 0.977 & 0.332 & 11.652 & $* * *$ \\
APRN & $<---$ & RANTAI_NILAI & 0.991 & 0.566 & 12.783 & $* * *$ \\
AURN & $<---$ & RANTAI_NILAI & 0.987 & 0.364 & 16.599 & $* * *$
\end{tabular}




\begin{tabular}{|c|c|c|c|c|c|c|}
\hline DPIT & $<--$ & DAYA_SAING & 0.631 & 0.363 & 6.903 & $* * *$ \\
\hline KBIT & $<--$ & DAYA_SAING & 0.981 & 0.304 & 13.98 & $* * *$ \\
\hline Y113 & $<--$ & KFIT & 0.661 & 0.083 & 10.194 & $* * *$ \\
\hline Y122 & $<---$ & KPIT & 0.708 & 0.101 & 10.245 & $* * *$ \\
\hline Y123 & $<---$ & KPIT & 0.538 & 0.094 & 7.975 & $* \star \star$ \\
\hline Y132 & $<---$ & FSSP & 0.613 & & & \\
\hline Y133 & $<---$ & FSSP & 0.553 & 0.12 & 7.515 & $* * *$ \\
\hline Y134 & $<---$ & FSSP & 0.637 & 0.097 & 9.854 & $* \star \star$ \\
\hline $\mathrm{X} 112$ & $<---$ & AURN & 1.309 & 0.135 & 10.934 & $* * *$ \\
\hline $\mathrm{X} 113$ & $<---$ & AURN & 0.908 & 0.066 & 15.405 & $* * *$ \\
\hline $\mathrm{X} 115$ & $<---$ & AURN & 0.906 & & & \\
\hline Y121 & $<---$ & KPIT & 0.695 & & & \\
\hline X124 & $<---$ & APRN & 0.828 & & & \\
\hline $\mathrm{X} 123$ & $<---$ & APRN & 0.648 & 0.073 & 8.591 & $* * *$ \\
\hline Y142 & $<---$ & FTIM & 0.789 & 0.092 & 13.15 & $* * *$ \\
\hline Y141 & $<---$ & FTIM & 0.684 & & & \\
\hline Y143 & $<---$ & FTIM & 0.769 & 0.093 & 10.862 & $* * *$ \\
\hline Y114 & $<---$ & KFIT & 0.748 & & & \\
\hline Y112 & $<---$ & KFIT & 0.662 & 0.075 & 12.217 & $* \star *$ \\
\hline Y153 & $<---$ & DPIT & 0.686 & & & \\
\hline Y154 & $<---$ & DPIT & 0.88 & 0.154 & 7.961 & $* * *$ \\
\hline Y164 & $<---$ & KBIT & 0.729 & & & \\
\hline Y162 & $<---$ & KBIT & 0.701 & 0.078 & 13.544 & $* * *$ \\
\hline
\end{tabular}

Keterangan:

${ }^{\star \star *}=$ nilai probability signifikan pada $\alpha=5 \%$

Setelah memenuhi semua ukuran fitting model, maka dihitung nilai reliabilitasnya.

Construct Reliability $=\frac{(23.691)^{2}}{(23.691)^{2}+10.362}=0.982$

Karena nilai Contruct Reliability nya $=0.982>0.7$ maka dapat disimpulkan model adalah reliabel. Model pengaruh Sistem Rantai Nilai Perikanan Tuna terhadap Daya Saing Industri Perikanan Tuna dapat dituliskan sebagai berikut:

Daya Saing $=0.54^{*}$ Rantai Nilai

\section{Pengaruh Rantai Nilai terhadap Daya Saing Industri Tuna}

Hipotesis yang pertama yang diteliti adalah pengaruh sistem rantai nilai perikanan tuna terhadap daya saing industri perikanan tuna (DSIT). Hasil penelitian yang ditunjukkan pada Tabel 8 menjelaskan bahwa rantai nilai memiliki pengaruh terhadap daya saing industri perikanan tuna (DSIT). Hal itu dapat ditunjukkan dengan nilai loading factor $=0.54$ dengan $C R=9.676$ dan $p=0.000$. Dengan demikian pengaruh rantai nilai perikanan tuna terhadap daya saing industri perikanan tuna dalam model keseluruhan adalah nyata, dan menghasilkan pengaruh yang signifikan. Oleh karena itu implikasinya adalah untuk meningkatkan daya saing dapat dilakukan dengan menata rantai nilai. Maka $\mathrm{H}_{1}$ terbukti.

\section{IMPLIKASI MANAJERIAL}

Hasil pengolahan data penelitian menunjukkan adanya pengaruh yang signifikan antara sistem rantai nilai perikanan tuna terhadap daya saing industri tuna, yang ditunjukkan oleh nilai loading factor dan nilai peluang yang signifikan.

\section{Implikasi terhadap Peningkatan Rantai Nilai Industri Ikan Tuna}

Hasil pengolahan data pada variabel aktivitas utama rantai nilai menunjukkan bahwa, indikator inbound logistic dan indikator marketing pada variabel rantai nilai harus didrop dari model. Kondisi tersebut sesuai dengan situasi di lapangan. Sebagaimana hasil pengamatan yang dilakukan, aktivitas inbound untuk produk tuna tidak menjadi permasalahan, begitu juga aktivitas marketing, hal ini dikarenakan hasil tangkapan tuna di kabupaten Cilacap semua diekspor 
melalui Jakarta. Aktivitas penyimpanan di gudang pelabuhan tidak diperlukan. Aspek marketing yang terjadi selama ini juga tidak ada, karena semua hasil tangkapan produk tuna tidak dijual secara bebas, semua hasil tangkapan tuna ditampung oleh perusahaan. Sehingga saat pelelangan di Pelabuhan Pendaratan Ikan tidak ada aktivitas bargaining atau tawar menawar harga. Kondisi seperti ini mengakibatkan nilai tawar dari nelayan sangat rendah, bahkan bias dikatakan tidak ada.

Hasil pengolahan data pada variabel aktivitas pendukung rantai nilai, indikator pengembangan infrastruktur dan pengembangan SDM rantai nilai tidak signifikan, sehingga harus di drop dari model. Temuan ini selaras dengan hasil pengamatan di lapangan bahwa peran infrastruktur dan SDM dalam rantai nilai perikanan tuna saat ini tidak terlalu menentukan. Modernisasi infrastruktur juga tidak cukup dapat meningkatkan bargaining nelayan, karena proses pelelangan berlangsung singkat dan sederhana. Indikator pembelian merupakan temuan penting, mengingat nelayan membutuhkan jaminan pembelian dengan harga yang baik. Perlunya regulasi pemerintah untuk menjamin pembelian dengan harga yang sesuai dengan kondisi pasar dunia. Indikator teknologi yang besar juga menunjukkan bahwa pentingnya peningkatan teknologi penangkapan dan penyimpanan agar diperoleh tuna hasil tangkapan yang mempunyai kualitas baik.

Temuan penelitian ini sebagaimana ditunjukkan oleh hasil pengolahan data menggunakan CFA terhadap model penelitian, yang perlu mendapat penekanan agar tercapai peningkatan kinerja rantai nilai adalah perlunya penguatan industri ikan tuna dari sektor hulu diantaranya adalah diperolehnya loading factor $(0.70-0.98)$ yang sangat signifikan terhadap:

1) Konstruk aktivitas utama rantai nilai, utamanya yang terdapat pada sektor operational dalam sistem rantai nilai industri tuna, outbond logistic dalam rantai nilai industri tuna dan services dalam sistem rantai nilai industri tuna.

2) Konstruk aktivitas pendukung rantai nilai utamanya pada faktor pengembangan teknologi rantai nilai industri tuna dan pembelian dalam sistem rantai nilai industri tuna.

\section{Implikasi terhadap Peningkatan daya saing Industri Ikan Tuna}

Hasil pengolahan data menggunakan Confirmatory Factor Analysis terhadap model penelitian, pada konstruk utama yang perlu medapat penekanan agar tercapai peningkatan daya saing adalah:
1) Kondisi faktor industri tuna, yang meliputi teknologi industri tuna, modal kerja industri tuna, tenaga kerja industri tuna dan bahan baku industri tuna perlu mendapat perhatian dari pemerintah.

2) Kondisi permintaan industri tuna, yang meliputi tuntutan pelanggan industri tuna, akses pasar industri tuna dan kualitas produk industri tuna.

3) Faktor struktur, strategi dan persaingan, dengan indikator efisiensi biaya produksi industri tuna, penurunan harga produk industri tuna, kemampuan manajerial industri tuna dan strategi bersaing industri tuna.

4) Faktor industri terkait dan mendukung, dengan indikator: keterkaitan bisnis industri lain, kekuatan industri pendukung dan dukungan teknologi industri pendukung.

5) Kesempatan bisnis industri tuna, meliputi minat investasi pada industri tuna, perbaikan teknologi pada industri tuna, perbaikan kondisi sosial politik dan peningkatan preferensi konsumen dunia.

Sedangkan faktor dukungan pemerintah terhadap industri tuna, dengan indikator: bantuan teknis pada industri tuna \& bantuan dana pada industri tuna tidak signifikan dalam meningkatkan daya saing. Kualitas kontrol terhadap industri tuna dan konservasi perikanan tuna Indonesia didapatkan loading factor yang cukup besar, sehingga dapat dikatakan sebagai indikator yang penting dalam mendukung rantai nilai perikanan tuna. Hal ini mengandung pengertian bahwa kebijakan Pemerintah pada sektor bantuan teknis dan pendanaan selama ini sudah cukup memadai. Faktor yang masih harus ditingkatkan adalah kebijakan pemerintah dalam menjamin tercapainya kualitas tuna dan kebijakan yang menjamin sustainability perikanan tuna di wilayah Cilacap.

\section{KESIMPULAN DAN REKOMENDASI Kesimpulan}

Rantai nilai mempunyai kontribusi yang signifikan terhadap daya saing industri ikan tuna di Kabupaten Cilacap, yang ditunjukkan oleh besarnya nilai loading factor 0.54 dengan nilai $p$ signifikan dan dipenuhinya semua ukuran fitting model. Ditemukan bahwa rantai nilai mempunyai kontribusi yang besar terhadap daya saing industri tuna di Cilacap. Dengan melakukan perbaikan sistem rantai nilai perikanan terutama pada aspek operasional, outbond logistic, dan services maka akan dapat memberikan kontribusi dan perbaikan terhadap peningkatan daya saing industri tuna di Kabupaten Cilacap. Selain itu, untuk meningkatkan daya saing perlu dilakukan peningkatan aspek sumberdaya manusia dan perbaikan infrastruktur. 


\section{Rekomendasi}

Agar peningkatan daya saing industri perikanan tuna dapat tercapai maka harus dilakukan penataan terhadap peraturan dan kebijakan pada aspek rantai nilai perikanan tuna di Kabupaten Cilacap serta harus dilakukan pengawasan terhadap implementasi di lapangan. Kebijakan yang dilakukan pemerintah saat ini sebenarnya sudah cukup baik, akan tetapi implementasi di lapangan serta pengawasannya masih kurang efektif. Untuk itu, kedepan diperlukan penguatan aspek kelembagaan dan peningkatan pengawasan dalam implementasi kebijakan dilapangan.

\section{PERSANTUNAN}

Terimakasih diucapkan kepada Kepala Pelabuhan Pendaratan Ikan Samudra Cilacap yang telah memberikan ijin kepada peneliti untuk melakukan pengumpulan data di PPI Cilacap. Terimakasih juga diucapkan kepada seluruh team yang telah membantu pada proses pengumpulan data di lapangan.

\section{DAFTAR PUSTAKA}

Acharyulu, S. G., Subbaiah, K. V., \& Rao, K. N. (2015). Value chain model for steel manufacturing Sector: A Case Study. International Journal of Managing Value and Supply Chains. 45-53.

Al-Hawari, M., Hartley, N., \& Ward, T. (2005). Measuring banks' automated service quality: A Confirmatory Factor Analysis Approach. Marketing Buletin. 1-19.

Crisci, A. (2012). Estimation methods for the structural equation models: Maximum Likehood, Partial Least Square and Generalized Maximum Entrophy. JAQM. 1-15.

Dimitrov, D. M. (2006). Comparing groups on latent variables: Astructural equation modeling approach. Work 26. 429-436.

Doll, W. J., Raghunathan, T. S., Lim, J. S., \& Gupta, Y. P. (1995). A Confirmatory factor Analysis of the User Information Satisfaction Instrument. Information System Research. 177-179.

Ebders, A., Konig, A., Hungenberg, H., \& Engelbertz, T. (2000). Toward an integrated perspective of strategy: The Value Process Framework. Journal of Strategy and Management. 76-96.
FAO. (2015), "Fish Outlook 2015-2024 and 2030," Technical, Food and Agriculture Organization of the United Nation.

Felipe, J. (1997). Total factor productivity growth in East Asia: A Critical Survey. Manila: Asian Development Bank.

Galland, G., Rogers, A., \& Nickson, A. (2016). Netting billions: A Global Valuation of Tuna. The PEW Charitable Trust. 1-28.

Kim, M. (1985). Total factor productivity in Bus Transport . Journal of Transport Economic and Policy, 173-182.

Kumar, P. J., Subbaiah, K. V., \& Rao, N. (2013). Identification of SWOT variables for supplier selection through confirmatory factor analysis - A Case Study. International Journal of Mechanical and Production. 19-26.

Lailossa, G. W. (2015). The new paradigm of cold chain management systems and It's logistics on Tuna Fishery Sector in Indonesia. AACL Bioflux. 381-390.

Maat, S. M., Adnan, M., Abdullah, M. F., Ahmad, C. N., \& Puteh, M. (2015). Confirmatory factor analysis of learning environment instrument among high performance school student. Creative Education. 640-646.

O'Mahony, M., \& Vecchi, M. (2002). Is There an ICT Impact on TFP? A heterogeneous dynamic panel approach. Discussion Papers-National Institute.

Ondrej, M., \& Jiri, H. (2012). Total factor productivity approach in competitive and regulated World. International Conference on Asia Pacific Business Innovation and Technology Management. 223-230.

Pavlina, P. (2015). The factors influencing satisfaction with Public City Transport: A Structural Equation Modelling Approach. Journal of Competitiveness. 18-32.

Pemerintah Provinsi Jawa Tengah. (2016). Laporan tahunan statistik perikanan. Dinas Kelautan dan Perikananan Propinsi Jawa Tengah.

Porter, M. (2004). Building the microeconomic foundation of prosperity (A Lopez-Claroz (Ed) ed.). New York: Palgrave Macmillan. 
Porter, M. E. (1985). Competitive advantage: Creating and Sustaining Superior Performance. New York: The Free Press.

Porter, M. E. (1990). Competitive advantage of Nations. New York: The Free Press.

Porter, M. E. (1998). Cluster and the new economic of competition. Harvard Bussiness Review. 1-77.

PPS-Cilacap. (2016). Laporan tahunan statistik.

Safiih, M. L., \& Azreen, N. M. (2016). Confirmatory factor analysis approach: A Case Study of
Mathematics Students' Achievement in TIMSS. Malaysian Journal of Mathematical Sciences. 4151.

Suhana. (2015). Development of Indonesia Marine in 2014. ResearchGate.

Ullman, J. B. (2001). Structural equation modeling. In B. G. Tabachnick \& L. S. Fidell (Eds.), Using multivariate statistics (4th ed.). Needham: MA: Allyn \& Bacon. 